\title{
Effects of Low-Intensity Laser Irradiation on Wound Healing in Diabetic Rats
}

\author{
Hui Ma, ${ }^{1,2}$ Ying-xin Li, ${ }^{2,3}$ Hong-li Chen,, ${ }^{1,2}$ Mei-ling Kang, ${ }^{1,2}$ and Timon Cheng-Yi Liu ${ }^{4}$ \\ ${ }^{1}$ School of Biomedical Engineering, Tianjin Medical University, Tianjin 300070, China \\ ${ }^{2}$ Tianjin Laser Medical Technology Engineering Center, Tianjin 300350, China \\ ${ }^{3}$ Institute of Biomedical Engineering, Chinese Academy of Medical Science \& Peking Union Medical College, Tianjin 300192, China \\ ${ }^{4}$ Laboratory of Laser Sports Medicine, South China Normal University, Guangzhou 510006, China \\ Correspondence should be addressed to Ying-xin Li, yingxinli2005@yahoo.com.cn
}

Received 19 October 2011; Revised 3 December 2011; Accepted 19 December 2011

Academic Editor: Rui Duan

Copyright ( $) 2012$ Hui Ma et al. This is an open access article distributed under the Creative Commons Attribution License, which permits unrestricted use, distribution, and reproduction in any medium, provided the original work is properly cited.

Objective. The effects of low-intensity $630 \mathrm{~nm}$ semiconductor laser irradiation at $3.6 \mathrm{~J} / \mathrm{cm}^{2}$ (LISL) on wound healing in diabetic rats were studied in this paper. Methods. 36 diabetic rats with dorsal cutaneous excisional wounds were divided into three LISL groups and a control group randomly. The three LISL groups were irradiated with LISL at 5, 10, and $20 \mathrm{~mW} / \mathrm{cm}^{2}$ five times a week for two weeks, respectively. The process of wound healing was assessed by assessing blood glucose, calculating percentage of wound closure, histopathological evaluation, and immunohistochemical quantification. Results. Blood glucose of all groups remained at similar levels throughout the experiment. LISL could obviously promote wound contraction, fibroblasts proliferation, and collagen synthesis, alter bFGF and TGF- $\beta 1$ expression, and reduce inflammatory reaction in the early and middle phases of chronic wound-healing process. However, LISL could not shorten cicatrization time, and the treatment effects were not sensitive to illuminate parameters in the later phase of the experiment. Conclusions. LISL might have auxiliary effects in the early and middle phases of wound healing in STZ-induced diabetic rats, but the reciprocity rule might not hold. The wound-healing process of early-phase diabetes rats shows typical characteristics of self-limited disease.

\section{Introduction}

Diabetes is a complex metabolic disorder involving many body organs and systems and can devastate the lives of affected individuals [1]. It is estimated that global prevalence of diabetes gets to $6.6 \%$ (285 million people) in 2010, and the number of people with diabetes will have risen to 438 million or $7.8 \%$ of the world's population by 2030 [2]. Impaired wound healing is a complication of diabetes and a serious problem in clinical practice [3]. As many as 15\% of people with diabetes will develop foot ulceration and wounds, and $3 \%$ will have a lower limb amputation $[4,5]$.

Photobiomodulation (PBM) is a modulation of laser irradiation (LI) or monochromatic/broad band light on biosystems, which stimulates or inhibits biological functions but does not result in irreducible damage. The LI used in PBM is always low intensity-LI (LIL), $\sim 10 \mathrm{~mW} / \mathrm{cm}^{2}$. However, moderate-intensity LI (MIL), $10^{2 \sim 3} \mathrm{~mW} / \mathrm{cm}^{2}$, is of
PBM if the irradiation time is not so long that it damages organelles or cells.

In recent years, PBM has gained considerable recognition and importance among treatment modalities for various medical problems including wound repair processes, musculoskeletal complications, and pain control [6-8]. Many literatures were reported that PBM can promote the healing process by reducing pain and inflammation, promoting cells proliferation, facilitating collagen synthesis, fostering immunity, and increasing wound tensile strength [4, 8-12].

A substantial amount of studies show that PBM with appropriate treatment parameters can promote the chronic wound healing in diabetic rats [13-15]. LI at $630 \mathrm{~nm}$ in visible red-light region was generally believed as the optimum wavelength, but significant beneficial effects have also been observed on diabetic rats for LI at 532, 810, and $980 \mathrm{~nm}$ [4]. Range of power density options varied considerably (from LIL to MIL). It's worth noting that 
TABLE 1: Groups of experiment and treatment parameters.

\begin{tabular}{|c|c|c|c|c|c|}
\hline & $\begin{array}{c}\text { Power density } \\
\left(\mathrm{mW} / \mathrm{cm}^{2}\right)\end{array}$ & $\begin{array}{l}\text { Irradiation time } \\
(\mathrm{min})\end{array}$ & Energy density $\left(\mathrm{J} / \mathrm{cm}^{2}\right)$ & $\begin{array}{c}\text { Treatment schedule } \\
\text { (times/week) }\end{array}$ & Number of rats \\
\hline Control group & 0 & 0 & 0 & 0 & 9 \\
\hline $5 \mathrm{~mW} / \mathrm{cm}^{2}$ group & 5 & 12 & 3.6 & 5 & 9 \\
\hline $10 \mathrm{~mW} / \mathrm{cm}^{2}$ group & 10 & 6 & 3.6 & 5 & 9 \\
\hline $20 \mathrm{~mW} / \mathrm{cm}^{2}$ group & 20 & 3 & 3.6 & 5 & 9 \\
\hline
\end{tabular}

a lately study by Akyol and Güngörmüş [8] suggested that $808 \mathrm{~nm}$ MIL at $100 \mathrm{~mW} / \mathrm{cm}^{2}$ has a beneficial effect on the early recovery of skin incisions in female Wistar rats with streptozotocin (STZ)-induced diabetes. There were significant differences between the MIL group and control group in both reepithelialization and inflammation at 10th day. However, the differences disappeared both in inflammation and reepithelialization at 20th day. This is typical of selflimited disease, which indicates that the wound of early phase diabetes can heal completely by itself. Similar phenomenon had been mentioned in conventional wound-healing process $[16,17]$. Recently, a research even suggested that diabetes may be also self-limited, and the abnormalities underlying diabetes are reversible [18].

The aims of our paper was to study the effects of lowintensity laser irradiation (LIL) on the wound healing of male Wistar rats with STZ-induced diabetes. With more detailed and comprehensive methods than Akyol et al.'s study, we tried to gain better insight into the healing process more deeply, to verify the characteristics of self-limited disease in the wound-healing process, and to offer an appropriate intensity at $3.6 \mathrm{~J} / \mathrm{cm}^{2}$ for further study.

\section{Material and Methods}

2.1. Animals. Thirty-six male Wistar rats weighing 220-250 g from the animal house of Institute of Radiation Medicine Chinese Academy of Medical Sciences were used in this study. During the study, the rats were housed 9 per cage, maintained under controlled environmental conditions (12hours light/dark cycle, temperature $23^{\circ} \mathrm{C}$ ), and provided with standard laboratory food and water ad libitum.

2.2. Induction of Diabetes. Diabetes was chemically induced using STZ (Sigma Co., USA), $40 \mathrm{mg} / \mathrm{kg}$, dissolved in citrate buffer ( $\mathrm{pH}$ 4.4) and administered as tail vein injection in all rats. Seven days after STZ injection, blood glucose levels were measured using a glucometer and test strips (One Touch Ultra; IifeScan Co., USA), and all STZ-injected rats with a blood glucose of $16.5 \mathrm{mmol} / \mathrm{L}$ or more were included in the protocol.

2.3. Wound Surgery. Before surgery, the blood glucose level of each rat was checked again. Each rat was anesthetized with $10 \%$ chloral hydras $(300 \mathrm{mg} / \mathrm{kg}$ ) intraperitoneally. The hair on the dorsum of all rats was shaved using an electric clipper. The operative site was prepared aseptically. Two incisions (10 $\mathrm{mm} * 10 \mathrm{~mm}$ square) were made on the dorsum of each rat using a steel scalpel (Rockwell number 15). One incision was performed on the left side of the dorsum and the other was on the right.

2.4. Groups of Experiment and Treatment Parameters. Thirtysix rats were randomly divided into 4 groups: $5 \mathrm{~mW} / \mathrm{cm}^{2}$ group, $10 \mathrm{~mW} / \mathrm{cm}^{2}$ group, $20 \mathrm{~mW} / \mathrm{cm}^{2}$ group, and control group, 9 rats per group. The study was performed using a $630 \mathrm{~nm}$ continuous semiconductor laser system designed by Laser Medical Laboratory of Institute of Biomedical Engineering, Chinese Academy of Medical Science \& Peking Union Medical College. The output power was measured using a laser power meter (SOLO PE; Gentec-EO Inc., Canada). The laser treatment parameters are listed in Table 1. PBM was started immediately after surgery and repeated 5 times/week for two weeks. The laser beam was aligned to cover the entire wound area, including the boundaries.

2.5. Blood Glucose Level. Before surgery and 14 days after wounding, the blood glucose level of each rat was checked.

Average blood glucose was presented as mean blood glucose \pm SEM and compared with Matching $T$ test.

2.6. Percentage of Wound Closure. At 3, 6, 9, and 12 days after wounding, the areas of wounds on all rats were recorded with standardized photography, and calculated the percentage of wound closure by ImageJ (http://rsb.info.nih.gov/ij/). Percentage of wound closure was calculated using the following formula [19]: [(Area of 1 Day - Area of X Days)/Area of 1 Day] $\times 100 \%$. Average wound closure percentage was presented as mean percentage \pm SEM and compared with one-way ANOVA with Tukey posttest.

2.7. Histopathological Evaluation. At 4, 8, and 14 days after wounding, 3 rats were chosen from each group randomly and killed by ether inhalation. The tissue specimens were stained with hematoxylin and eosin, examined with a semiquantitative method [10] to evaluate following histological features: polymorphonuclear leukocytes (PMNLs), reepithelization, fibroblasts, new vessels, and collagen synthesis. The sections were studied by two independent observers and evaluated on a scale of 0-4. Observers were blinded for the study of the specimens. Average semiquantitative evaluation score was presented as mean score \pm SEM and compared with the nonparametric Kruskal-Wallis test.

2.8. Immunohistochemical Quantification. At 4, 8, and 14 days after wounding, the tissue specimens were fixed for 24 


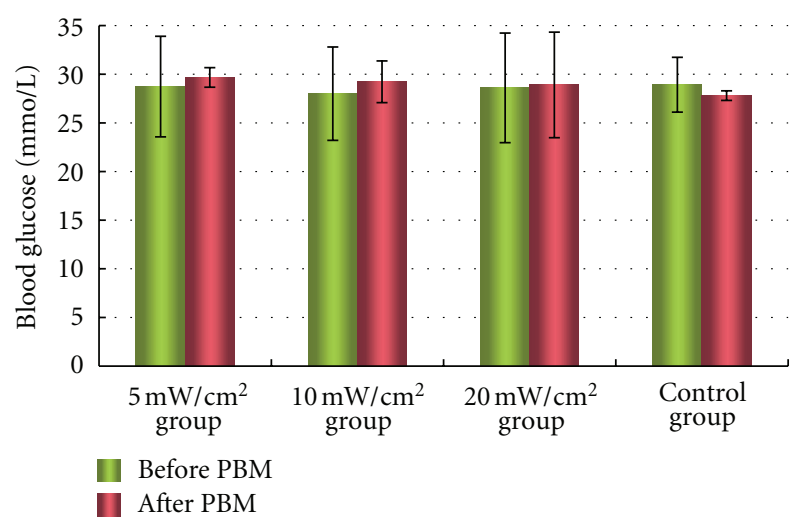

FIGURE 1: Blood glucose levels of all groups throughout the experiment.

hours in 4\% paraformaldehyde prior to being embedded in paraffin and sectioned (longitudinal section perpendicular to wound surface, $5 \mu \mathrm{m}$ ). The tissue was deparaffinized, rehydrated, and blocked with an appropriate blocking solution. Tissue was incubated at $4{ }^{\circ} \mathrm{C}$ overnight with an antibody to basic fibroblast growth factor (bFGF) (SC-79; Santa Cruz Inc., USA) or transforming growth factor $\beta 1$ (TGF- $\beta 1$ ) (SC146; Santa Cruz Inc., USA) followed by incubation with secondary antibody at $37^{\circ} \mathrm{C}$ for 20 minutes. Choose $5 \mathrm{sec}-$ tions per slide, analysis and read the immunohistochemical score (Image-Pro Plus; Media Cybernetics Inc., USA) using a method modified from that described by Soslow et al. [20]. Average immunohistochemical score (IHS) was presented as mean IHS \pm SEM and compared with one-way ANOVA with Tukey posttest.

\section{Results}

3.1. Blood Glucose Level. There was no significant difference among diabetic rats that had been randomly placed into the 4 groups at the beginning of the experiment $(P>0.05)$. Blood glucose remained at similar levels throughout the experiment, with no significant difference between values before and after PBM $(P>0.05)$. At the end of the experiment, blood glucose of all rats (both control group and three PBM groups) were still in pathological blood glucose range (more than $16.5 \mathrm{mmol} / \mathrm{L}$ ) with no significant difference $(P>0.05)$ (Figure 1$)$.

3.2. Percentage of Wound Closure. At 3 days after wounding, only wounds of $20 \mathrm{~mW} / \mathrm{cm}^{2}$ group closed significantly faster than control group $(P<0.05)$. Wound closure percentages of other groups showed no significant difference $(P>0.05)$.

At 6 and 9 days after wounding, wounds of all three PBM groups closed significantly faster than control group $(P<0.05)$, but there was no significant difference among $5 \mathrm{~mW} / \mathrm{cm}^{2}$ group, $10 \mathrm{~mW} / \mathrm{cm}^{2}$ group, and $20 \mathrm{~mW} / \mathrm{cm}^{2}$ group $(P>0.05)$.

At 12 days after wounding, percentage of wound closure in all groups remained at similar levels $(P>0.05)$ (Figure 2$)$.

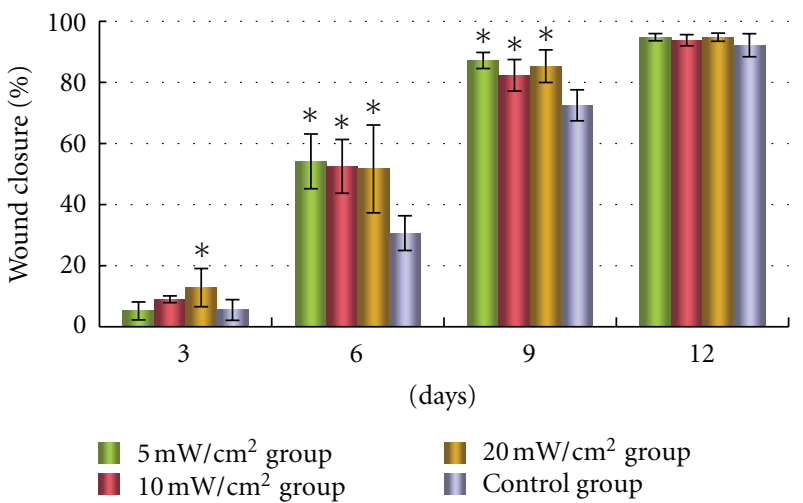

Figure 2: Percentage of wound closure throughout the experiment. Asterisk means that this group has statistical difference with control group $(P<0.05)$.

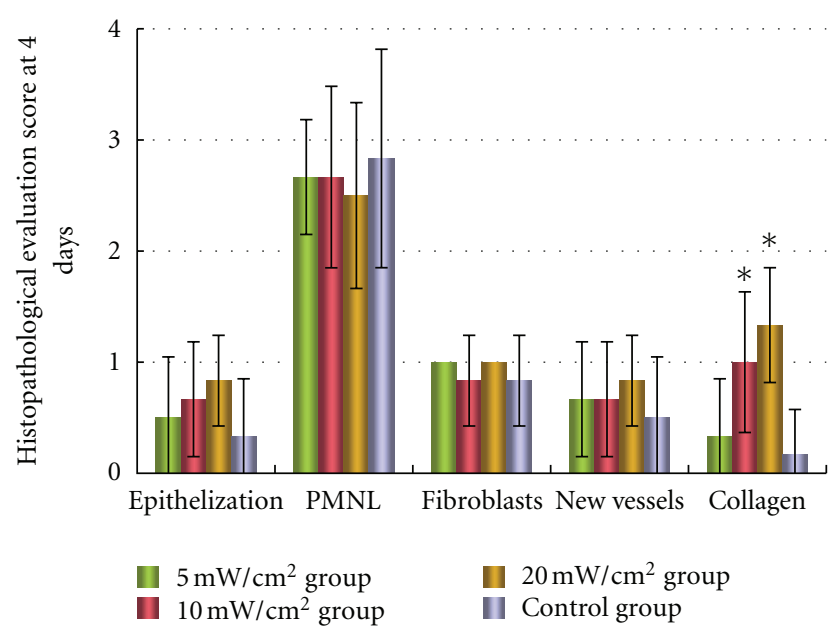

FIgURE 3: The semiquantitative histopathological evaluation score at 4 days after wounding. Asterisk means that this group has statistical difference with control group $(P<0.05)$.

\subsection{Histopathological Evaluation}

3.3.1. 4 Days. Remarkable inflammatory exudation and necrotic tissue could be observed in all tissue specimens. Comparable numbers of PMNLs, reepithelization, new vessels, and fibroblasts were recorded in all groups. However, there were significant differences in the creation of new collagen fibers between control group and $10 \mathrm{~mW} / \mathrm{cm}^{2}$ group $(P<0.05)$ or $20 \mathrm{~mW} / \mathrm{cm}^{2}$ group $(P<0.05)$ (Figure 3$)$.

3.3.2. 8 Days. Attenuated inflammation, mature granulation tissue, extensive collagen deposition, and greater reepithelization can be observed in three PBM groups. Control group had more inflammatory exudates and fresh granulation tissue (Figure 4).

The histological evaluation score of reepithelization, numbers of PMNLs, fibroblasts, and new collagen fibers, except for new vessels, shown significant differences between control group and $20 \mathrm{~mW} / \mathrm{cm}^{2}$ group $(P<0.05)$. There were significant differences in extensive fibroblasts and new 


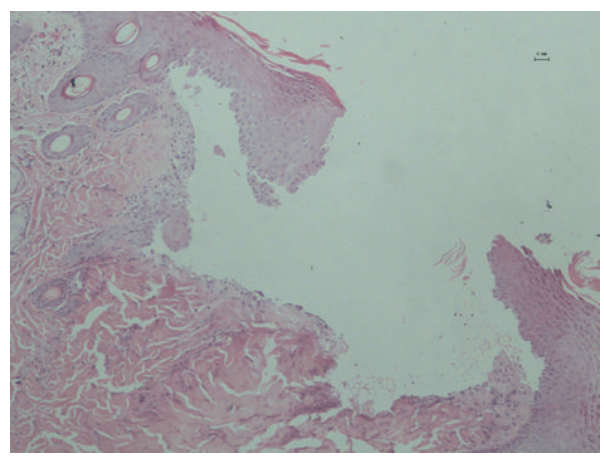

(a)

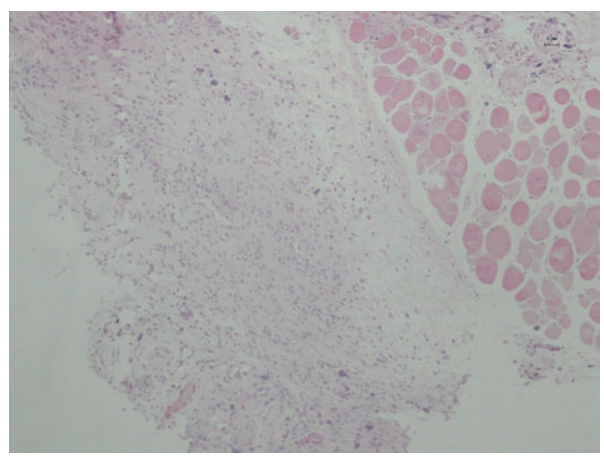

(b)

Figure 4: Photomicrograph of tissue samples from $20 \mathrm{~mW} / \mathrm{cm}^{2}$ group (a) and control group (b) at 8 days after wounding (HE stain $\times 100$ ).

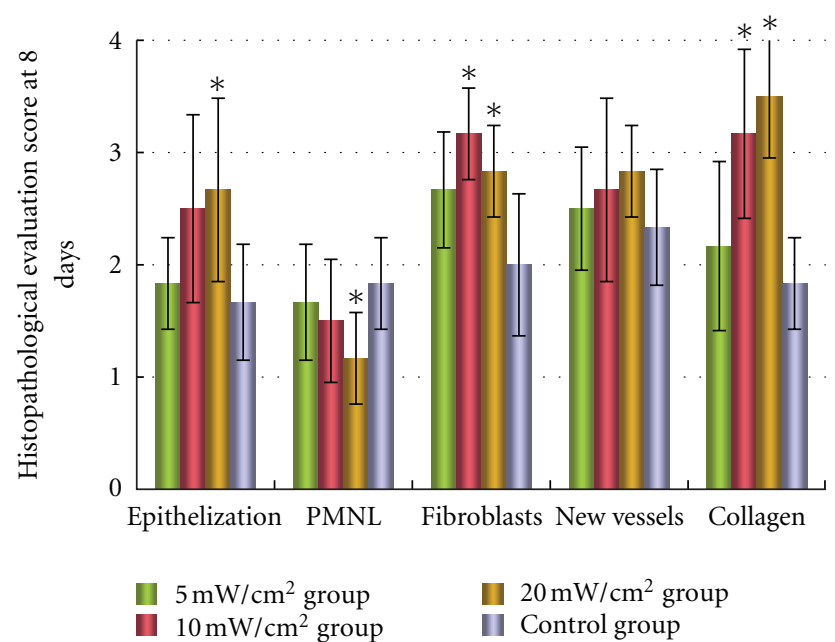

Figure 5: The semiquantitative histopathological evaluation score at 8 days after wounding. Asterisk means that this group has statistical difference with control group $(P<0.05)$.

collagen fibers between control group and $10 \mathrm{~mW} / \mathrm{cm}^{2}$ group $(P<0.05)$. The new vessels in all four groups were at similar level and had no significant differences $(P>0.05)$ (Figure 5).

3.3.3. 14 Days. New epithelial cells of all groups have covered almost all wounds, capillary gradually closed, granulation tissue gradually replaced with fibrous scar, fibroblasts decreased, and intercellular collagen content increased. The progress of wound healing in 4 groups was similar. However, there were significant differences in the evaluation score of new vessels between control group and $5 \mathrm{~mW} / \mathrm{cm}^{2}$ group or $20 \mathrm{~mW} / \mathrm{cm}^{2}$ group $(P<0.05)$, except $10 \mathrm{~mW} / \mathrm{cm}^{2}$ group (Figure 6).

3.4. Immunohistochemical Quantification. bFGF and TGF- $\beta 1$ protein expression at 4,8 , and 14 days after wounding revealed that growth factors were mainly located in the inflammatory cells (macrophages), granulation tissues (fibroblasts), and the surrounding newly formed capillaries.

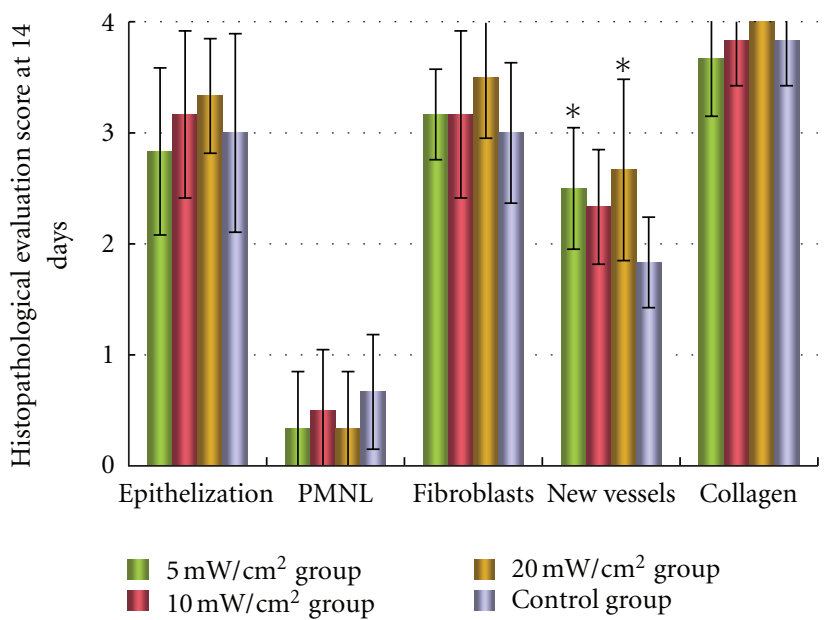

FIGURE 6: The semiquantitative histopathological evaluation score at 14 days after wounding. Asterisk means that this group has statistical difference with control group $(P<0.05)$.

IHS analysis revealed that bFGF expression in all PBM groups increased significantly compared with the control group $(P<0.05)$ at 4 days after wounding. $5 \mathrm{~mW} / \mathrm{cm}^{2}$ group had a significant bFGF increase in comparison to control group at 8 days after wounding $(P<0.05)$. There were no significant difference between irradiated groups and control group at 14 days after wounding $(P>0.05)$ (Figure 7).

TGF- $\beta 1$ protein expression in $10 \mathrm{~mW} / \mathrm{cm}^{2}$ group at 4 days after wounding increased significantly compared with other groups $(P<0.05)$. However, there were no significant differences between PBM groups and control group at 8 and 14 days after wounding $(P>0.05)$ (Figure 8$)$.

\section{Discussion}

The wound-healing process consists of four highly integrated and overlapping phases: hemostasis, inflammation, proliferation, and tissue remodeling [21]. It is widely accepted that chronic healing of diabetes wounds always accompanied with prolonged inflammation and decreased matrix accumulation [22]. 
TABLE 2: The differences of the animal models in two studies.

\begin{tabular}{lccccc}
\hline & Numbers of rats & The gender of rats & Wound surgery & $\begin{array}{c}\text { Wound size in length } \\
(\mathrm{mm})\end{array}$ & $\begin{array}{c}\text { Position of control group and LLLT } \\
\text { group }\end{array}$ \\
\hline Akyol et al.'s study & 18 & Female & Diode laser & 15 & On the same rat \\
Current study & 36 & Male & Steel scalpel & 10 & On different rats \\
\hline
\end{tabular}

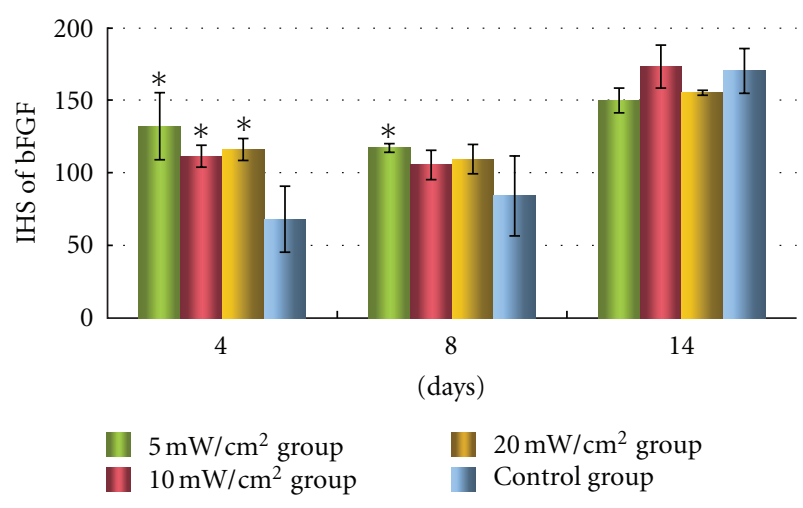

FIGURE 7: Immunohistochemical score (IHS) of bFGF protein expression throughout the experiment. Asterisk means that this group has statistical difference with control group $(P<0.05)$.

TABLE 3: The differences of the laser treatment parameters in two studies.

\begin{tabular}{lcccc}
\hline & $\begin{array}{c}\text { Wavelength } \\
(\mathrm{nm})\end{array}$ & $\begin{array}{c}\text { Power } \\
\text { density } \\
\left(\mathrm{mW} / \mathrm{cm}^{2}\right)\end{array}$ & $\begin{array}{c}\text { Energy } \\
\text { density } \\
\left(\mathrm{J} / \mathrm{cm}^{2}\right)\end{array}$ & $\begin{array}{c}\text { Total } \\
\text { treatment } \\
\text { times }\end{array}$ \\
\hline $\begin{array}{l}\text { Akyol et al.'s } \\
\text { study } \\
\begin{array}{l}\text { Current } \\
\text { study }\end{array}\end{array}$ & 808 & 100 & 2 & 5 \\
\hline
\end{tabular}

Our histopathological study found that attenuated inflammation, greater reepithelization, mature granulation tissue (fibroblasts), and extensive collagen deposition can be observed in PBM groups at 8 days after wounding, especially in $20 \mathrm{~mW} / \mathrm{cm}^{2}$ group. At the same time, the control group had more inflammatory exudates and fresh granulation tissue. These phenomena are consistent with the analysis of wound closure percentage data that PBM can obviously promote wound contraction, especially among 6-9 days after wounding. Results from our investigation are also in agreement with some previous published studies [10, 23, 24] that PBM are able to promote wound healing by reducing inflammation without compromising the proliferation of fibroblasts and keratinocytes.

The process of wound healing is precisely executed and regulated by a number of growth factors spatially and temporally. As is known to all, bFGF has potent effects on woundhealing process. It plays a vital role in regulating the synthesis and deposition of various extracellular medium components, increasing keratinocyte motility during reepithelization, and promoting the migration of fibroblasts and collagenase production [25-29]. TGF- $\beta 1$ has increased expression from

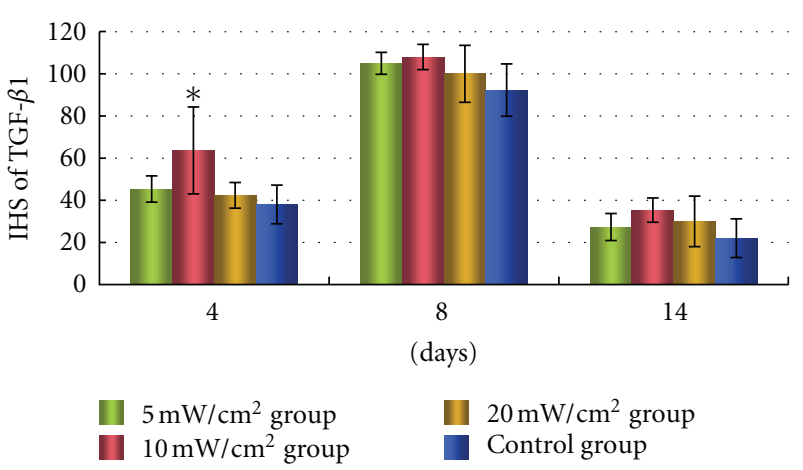

FIgure 8: Immunohistochemical score (IHS) of TGF- $\beta 1$ protein expression throughout the experiment. Asterisk means that this group has statistical difference with control group $(P<0.05)$.

the very beginning of injury and is of particular importance to modulate events of wounding healing [25]. TGF- $\beta 1$ enhances the wound repair by influencing cells proliferation and migration, angiogenesis, extracellular matrix synthesis, and deposition [30, 31].

Our current study investigated that the amount of growth factor productions was significantly altered in diabetic wounds with LIL, especially at 4 days after wounding. The results suggest that LIL promoted wound-healing process by influencing the levels of relevant growth factors, and then promoting cells proliferation and migration, regulating extracellular matrix synthesis and deposition. These are consistent with the aforementioned pathological analysis. It should point out that some growth factors protein expression always decrease in chronic healing wounds $[25,32]$. It appeared that the LIL might be a candidate to replace growth factors in clinically treatment [33].

Some literatures have reported that PBM increases bFGF immunolabeling rather than gene expression [19, 34]. It suggested that the observed bFGF immunolabeling increase might derive from bFGF secretion or protein production, instead of de novo synthesis. LIL is capable of activating the latent TGF- $\beta 1$ complex in vitro, and its expression pattern in vivo suggests that TGF- $\beta 1$ plays a central role in mediating the accelerated healing response [35]. In this study, LIL at $5 \mathrm{~mW} / \mathrm{cm}^{2}$ increased bFGF protein expression at 4 or 8 days after wounding, LIL at $10 \mathrm{~mW} / \mathrm{cm}^{2}$ increased both bFGF and TGF- $\beta 1$ protein expression at 4 days after wounding, but LIL at $20 \mathrm{~mW} / \mathrm{cm}^{2}$ increased bFGF protein expression only at 4 days after wounding. The variation of $\mathrm{bFGF}$ in the $5 \mathrm{~mW} / \mathrm{cm}^{2}$ group at 8 days is much smaller compared to those of other groups. This may explain why only this group had a statistically significant increase in bFGF compared to the control group. However, the expression pattern of TGF- $\beta 1$ 
TABLE 4: The differences of the evaluate parameters in two studies.

\begin{tabular}{|c|c|c|c|}
\hline & research methods & Evaluate parameters & Observate time (after wounding) \\
\hline Akyol et al.'s study & Histopathological evaluation & Reepithelialization; inflammation & 10 and 20 days \\
\hline Current study & $\begin{array}{c}\text { Morphology evaluation; } \\
\text { histopathological semievaluation; } \\
\text { immunohistochemical } \\
\text { quantification }\end{array}$ & $\begin{array}{l}\text { Wound closure percentage; PMNLs, } \\
\text { reepithelization, fibroblasts, new vessels, } \\
\text { and collagen synthesis; bFGF and TGF- } \beta 1 \\
\text { protein production }\end{array}$ & $\begin{array}{c}\text { 3, } 6,9 \text {, and } 12 \text { days for morphology } \\
\text { evaluation; } 4,8 \text {, and } 14 \text { days for } \\
\text { histopathological and } \\
\text { immunohistochemical evaluation }\end{array}$ \\
\hline
\end{tabular}

did not show any change after LIL at both 8 and 14 days after wounding in our study. The expression patterns in all PBM groups, both bFGF and TGF- $\beta 1$, were similar with control group at 14 days after wounding. In an attempt to further understand the impact of LIL on regulating relevant growth factors, further experiments with larger sample size and advanced technologies should be conducted.

According to the reciprocity rule, the same LI dose has the same PBM. It holds for MIL but does not for LIL. The latter was supported in this study. In addition, LIL at the same dose and different power densities exert different regulatory effects on bFGF ( 8 days after wounding) and TGF- $\beta 1$ (4 days after wounding) in our study. LIL at $20 \mathrm{~mW} / \mathrm{cm}^{2}$ performed more effective than the one at 5 or $10 \mathrm{~mW} / \mathrm{cm}^{2}$ in the evaluated histological parameters and wound contraction percentage. Moreover, taking the length of the treatment time into consideration, we may choose $20 \mathrm{~mW} / \mathrm{cm}^{2}$ in our further experiments with $630 \mathrm{~nm} 3.6 \mathrm{~J} / \mathrm{cm}^{2}$ continuous semiconductor laser and consider it as the optimum among the power densities we used.

It is worth noting that no matter what illuminate parameters we used (including control group), the wounds contracted mostly and various evaluated parameters were not sensitive to illuminate parameters (4 groups had similar pathologic and immunohistochemical scores) at 14 days after wounding. In other words, LIL cannot shorten cicatrization time, even though it performed positively in the early and middle phases of wound-healing process, which is similar with the study by Akyol and Güngörmüş [8] using MIL at $100 \mathrm{~mW} / \mathrm{cm}^{2}$. This is typical of self-limited disease, which means that the wound of early-phase diabetes can heal completely by itself without the laser therapy. Similar phenomenon had been mentioned in conventional woundhealing process $[16,17]$, but rarely reported in healing of diabetes wound. Interestingly, there existed a lot of distinctions between the study of Akyol et al's and ours (Tables 2, 3, and 4). Anyway, both LIL and MIL have undeniable effects to facilitate wound healing as an auxiliary treatment by diminishing inflammatory exudation, enhancing wound contraction, avoiding infection, and ameliorating local pain and tumefaction in the early and middle phases.

\section{Conclusions}

$630 \mathrm{~nm}$ LIL at $3.6 \mathrm{~J} / \mathrm{cm}^{2}$ might have auxiliary effects in the early and middle phases of wound healing of male Wistar rats with STZ-induced diabetes, but the reciprocity rule did not hold. The wound-healing process of early-phase diabetes rats shows typical characteristics of self-limited disease, and the laser therapy cannot shorten the wound cicatrization time.

\section{Acknowledgment}

This work was supported by National Science Foundation of China (60878061).

\section{References}

[1] A. K. Khuwaja, L. A. Khowaja, and P. Cosgrove, "The economic costs of diabetes in developing countries: some concerns and recommendations," Diabetologia, vol. 53, no. 2, pp. 389-390, 2010.

[2] R. Colagiuri, "Diabetes: a pandemic, a development issue or both?" Expert Review of Cardiovascular Therapy, vol. 8, no. 3, pp. 305-309, 2010.

[3] H. Rafehi, A. El-Osta, and T. C. Karagiannis, "Genetic and epigenetic events in diabetic wound healing," International Wound Journal, vol. 8, no. 1, pp. 12-21, 2011.

[4] F. A. H. Al-Watban, X. Y. Zhang, and B. L. Andres, "Lowlevel laser therapy enhances wound healing in diabetic rats: a comparison of different lasers," Photomedicine and Laser Surgery, vol. 25, no. 2, pp. 72-77, 2007.

[5] T. Mandrup-Poulsen, "Diabetes," British Medical Journal, vol. 316, no. 7139, pp. 1221-1225, 1998.

[6] S. Hagiwara, H. Iwasaka, K. Okuda, and T. Noguchi, "GaAlAs $(830 \mathrm{~nm})$ low-level laser enhances peripheral endogenous opioid analgesia in rats," Lasers in Surgery and Medicine, vol. 39, no. 10, pp. 797-802, 2007.

[7] A. Schindl, M. Schindl, H. Pernerstorfer-Schön, and L. Schindl, "Low-intensity laser therapy: a review," Journal of Investigative Medicine, vol. 48, no. 5, pp. 312-326, 2000.

[8] U. Akyol and M. Güngörmüş, "The effect of low-level laser therapy on healing of skin incisions made using a diode laser in diabetic rats," Photomedicine and Laser Surgery, vol. 28, no. 1 , pp. 51-55, 2010.

[9] P. Gál, M. Mokrý, B. Vidinský et al., "Effect of equal daily doses achieved by different power densities of low-level laser therapy at $635 \mathrm{~nm}$ on open skin wound healing in normal and corticosteroid-treated rats," Lasers in Medical Science, vol. 24, no. 4, pp. 539-547, 2009.

[10] K. Lacjaková, N. Bobrov, M. Poláková et al., "Effects of equal daily doses delivered by different power densities of lowlevel laser therapy at $670 \mathrm{~nm}$ on open skin wound healing in normal and corticosteroid-treated rats: a brief report," Lasers in Medical Science, vol. 25, no. 5, pp. 761-766, 2010.

[11] M. B. Kreisler, H. Al Haj, N. Noroozi, B. Willershausen, and B. d'Hoedt, "Efficacy of low level laser therapy in reducing postoperative pain after endodontic surgery-a randomized double blind clinical study," International Journal of Oral and Maxillofacial Surgery, vol. 33, no. 1, pp. 38-41, 2004. 
[12] S. Nakaji, C. Shiroto, M. Yodono, T. Umeda, and Q. Liu, "Retrospective study of adjunctive diode laser therapy for pain attenuation in 662 patients: detailed analysis by questionnaire," Photomedicine and Laser Surgery, vol. 23, no. 1, pp. 60 65, 2005.

[13] A. G. Maiya, P. Kumar, and S. Nayak, "Photo-stimulatory effect of low energy helium-neon laser irradiation on excisional diabetic wound healing dynamics in wistar rats," Indian Journal of Dermatology, vol. 54, no. 4, pp. 323-329, 2009.

[14] G. K. Reddy, L. Stehno-Bittel, and C. S. Enwemeka, "Laser photostimulation accelerates wound healing in diabetic rats," Wound Repair and Regeneration, vol. 9, no. 3, pp. 248-255, 2001.

[15] S. B. Rabelo, A. B. Villaverde, R. A. Nicolau, M. A. Castillo Salgado, M. D. S. Melo, and M. T. T. Pacheco, "Comparison between wound healing in induced diabetic and nondiabetic rats after low-level laser therapy," Photomedicine and Laser Surgery, vol. 24, no. 4, pp. 474-479, 2006.

[16] V. Prabhu, S. B. S. Rao, N. B. Rao, K. B. Aithal, P. Kumar, and K. K. Mahato, "Development and evaluation of fiber optic probebased helium-neon low-level laser therapy system for tissue regeneration-an in vivo experimental study," Photochemistry and Photobiology, vol. 86, no. 6, pp. 1364-1372, 2010.

[17] A. R. A. P. Medrado, L. S. Pugliese, S. R. A. Reis, and Z. A. Andrade, "Influence of low level laser therapy on wound healing and its biological action upon myofibroblasts," Lasers in Surgery and Medicine, vol. 32, no. 3, pp. 239-244, 2003.

[18] E. L. Lim, K. G. Hollingsworth, B. S. Aribisala, M. J. Chen, J. C. Mathers, and R. Taylor, "Reversal of type 2 diabetes: normalisation of beta cell function in association with decreased pancreas and liver triacylglycerol," Diabetologia, vol. 54, no. 10, pp. 2506-2514, 2011.

[19] K. R. Byrnes, L. Barna, M. Chenault et al., "Photobiomodulation improves cutaneous wound healing in an animal model of type II diabetes," Photomedicine and Laser Surgery, vol. 22, no. 4, pp. 281-290, 2004.

[20] R. A. Soslow, A. J. Dannenberg, D. Rush et al., "COX-2 is expressed in human pulmonary, colonic, and mammary tumors," Cancer, vol. 89, no. 12, pp. 2637-2645, 2000.

[21] S. Guo and L. A. DiPietro, "Factors affecting wound healing," Journal of Dental Research, vol. 89, no. 3, pp. 219-229, 2010.

[22] S. E. Thomson, S. V. McLennan, A. Hennessy et al., "A novel primate model of delayed wound healing in diabetes: dysregulation of connective tissue growth factor," Diabetologia, vol. 53, no. 3, pp. 572-583, 2010.

[23] P. M. do Nascimento, A. L. B. Pinheiro, M. Â. C. Salgado, and L. M. P. Ramalho, "A preliminary report on the effect of laser therapy on the healing of cutaneous surgical wounds as a consequence of an inversely proportional relationship between wavelength and intensity: histological study in rats," Photomedicine and Laser Surgery, vol. 22, no. 6, pp. 513-518, 2004.

[24] P. Gál, B. Vidinský, T. Toporcer et al., "Histological assessment of the effect of laser irradiation on skin wound healing in rats," Photomedicine and Laser Surgery, vol. 24, no. 4, pp. 480-488, 2006.

[25] S. Barrientos, O. Stojadinovic, M. S. Golinko, H. Brem, and M. Tomic-Canic, "Growth factors and cytokines in wound healing," Wound Repair and Regeneration, vol. 16, no. 5, pp. 585-601, 2008.

[26] Y. Sogabe, M. Abe, Y. Yokoyama, and O. Ishikawa, "Basic fibroblast growth factor stimulates human keratinocyte motility by Rac activation," Wound Repair and Regeneration, vol. 14, no. 4, pp. 457-462, 2006.
[27] W. Grellner, T. Georg, and J. Wilske, "Quantitative analysis of proinflammatory cytokines (IL- $1 \beta$, IL-6, TNF- $\alpha$ ) in human skin wounds," Forensic Science International, vol. 113, no. 1-3, pp. 251-264, 2000.

[28] G. Di Vita, R. Patti, P. D’Agostino et al., "Cytokines and growth factors in wound drainage fluid from patients undergoing incisional hernia repair," Wound Repair and Regeneration, vol. 14, no. 3, pp. 259-264, 2006.

[29] T. Sasaki, "The effects of basic fibroblast growth factor and doxorubicin on cultured human skin fibroblasts: relevance to wound healing," Journal of Dermatology, vol. 19, no. 11, pp. 664-666, 1992.

[30] S. M. Safavi, B. Kazemi, M. Esmaeili, A. Fallah, A. Modarresi, and M. Mir, "Effects of low-level He-Ne laser irradiation on the gene expression of IL- $1 \beta$, TNF- $\alpha$, IFN- $\gamma$, TGF- $\beta$, bFGF, and PDGF in rat's gingiva," Lasers in Medical Science, vol. 23, no. 3, pp. 331-335, 2008.

[31] Z. Kopecki, M. M. Luchetti, D. H. Adams et al., "Collagen loss and impaired wound healing is associated with c-Myb deficiency," Journal of Pathology, vol. 211, no. 3, pp. 351-361, 2007.

[32] M. C. Robson, "The role of growth factors in the healing of chronic wounds," Wound Repair and Regeneration, vol. 5, no. 1, pp. 12-17, 1997.

[33] T. I. Karu, "Multiple roles of cytochrome c oxidase in mammalian cells under action of red and IR-A radiation," IUBMB Life, vol. 62, no. 8, pp. 607-610, 2010.

[34] H. S. Yu, C. S. Wu, C. L. Yu, Y. H. Kao, and M. H. Chiou, "Helium-neon laser irradiation stimulates migration and proliferation in melanocytes and induces repigmentation in segmental-type vitiligo," Journal of Investigative Dermatology, vol. 120, no. 1, pp. 56-64, 2003.

[35] P. R. Arany, R. S. Nayak, S. Hallikerimath, A. M. Limaye, A. D. Kale, and P. Kondaiah, "Activation of latent TGF- $\beta 1$ by lowpower laser in vitro correlates with increased TGF- $\beta 1$ levels in laser-enhanced oral wound healing," Wound Repair and Regeneration, vol. 15, no. 6, pp. 866-874, 2007. 


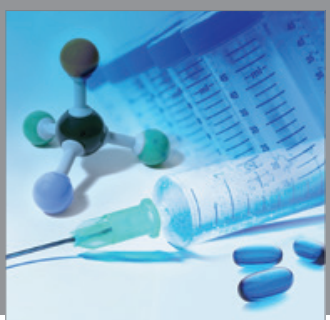

International Journal of

Medicinal Chemistry

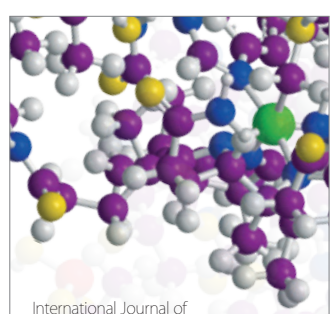

Carbohydrate Chemistry

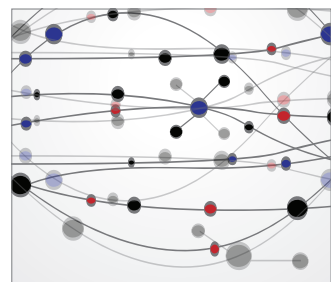

The Scientific World Journal
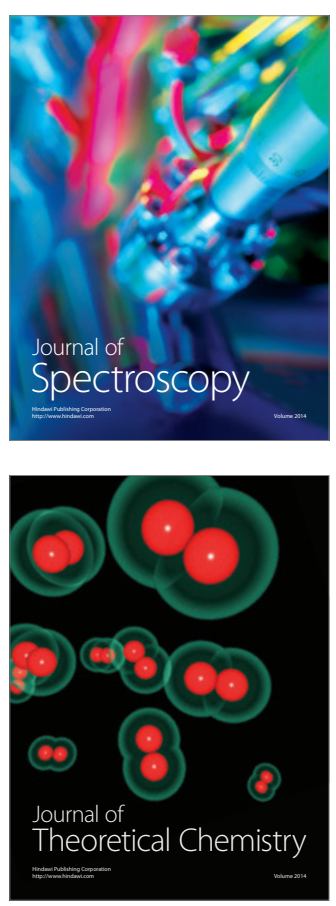
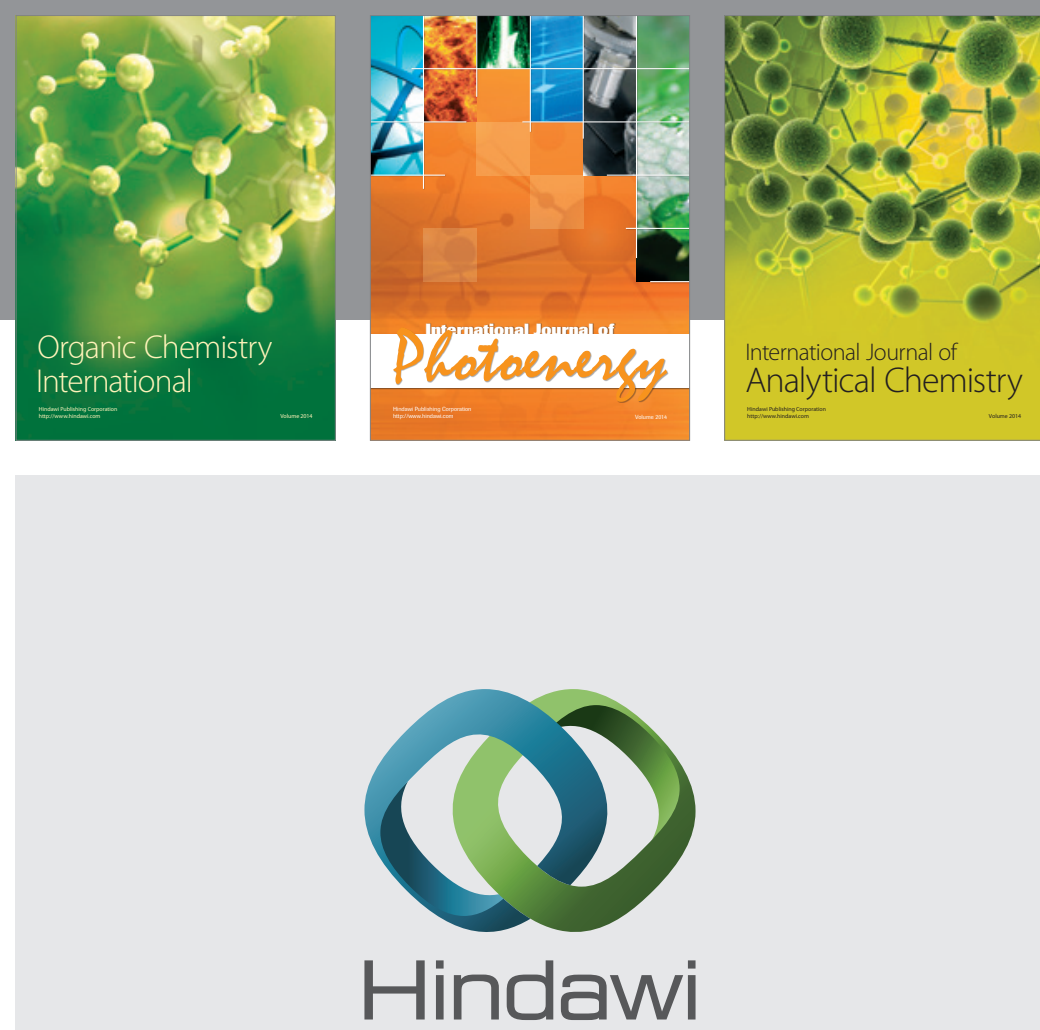

Submit your manuscripts at

http://www.hindawi.com
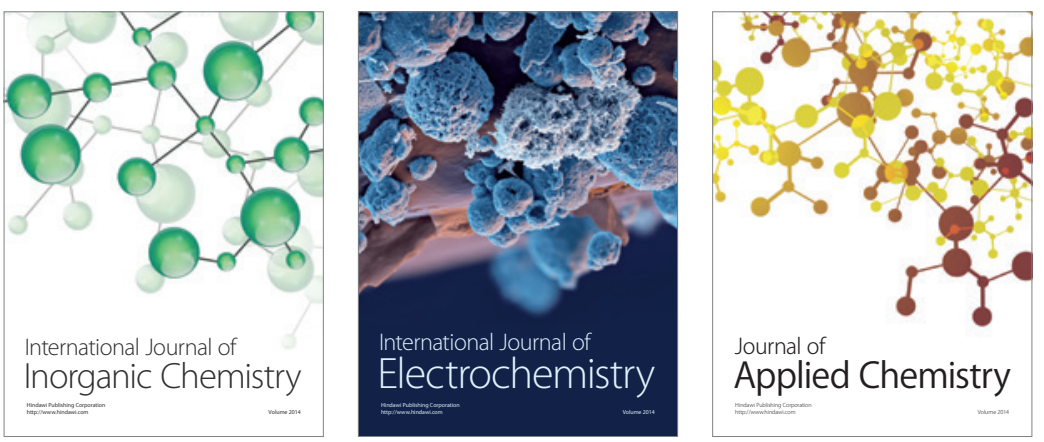

Journal of

Applied Chemistry
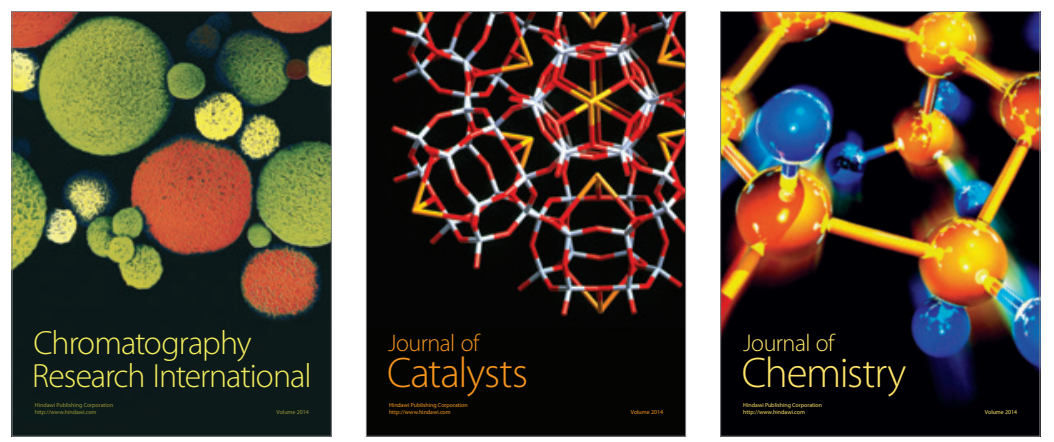
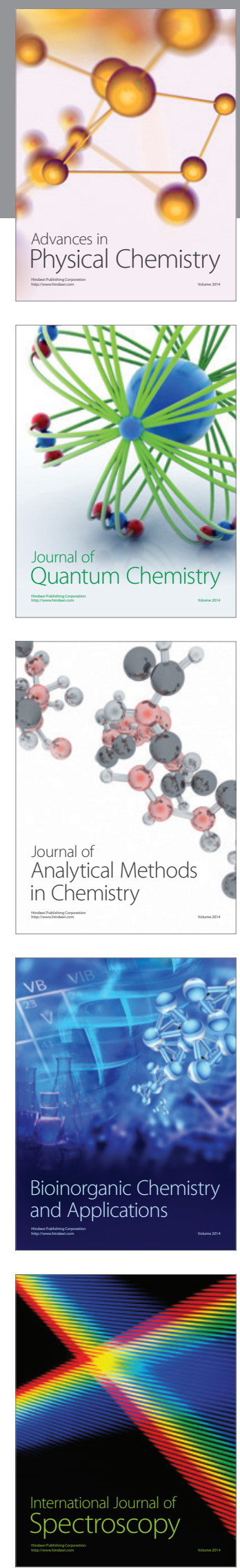